\title{
Culture and Identification of Candida Albicans from Vaginal Ulcer and Separation of Enolase on SDS-PAGE
}

\author{
P. Saravana Bhavan (Corresponding author) \\ Department of Zoology, Bharathiar University \\ Coimbatore 641046, Tamilnadu, India \\ Tel: 91-422-242-2222 Ext. $495 \quad$ E-mail: bhavanps@yahoo.co.in
}

R. Rajkumar

PRIDE, Periyar University

Salem 636011, Tamilnadu, India

E-mail: thrishrey@yahoo.co.in

S. Radhakrishnan

Department of Zoology, Bharathiar University

Coimbatore 641046, Tamilnadu, India

E-mail: radhas001@yahoo.com

C. Seenivasan

Department of Zoology, Bharathiar University

Coimbatore 641046, Tamilnadu, India

E-mail: crustaceanseenu@yahoo.com

S. Kannan

Department of Zoology, Bharathiar University

Coimbatore 641046, Tamilnadu, India

E-mail: skanmbt2000@yahoo.com

\begin{abstract}
Candida albicans were isolated from patients with clinical symptoms of vaginal ulcer. Culture test for vaginal swab and scrapings were conducted on Sabouraud's dextrose broth and Sabouraud's dextrose agar plate respectively. Hichrome candida agar culture was used for differential identification of Candida. Smears from vaginal scrapings were prepared for gram staining. The suspected strain of Candida was inoculated on corn meal agar medium for chlamydospore formation. The suspected strain of Candida was inoculated in human serum for germ tube formation. Carbohydrate assimilation and fermentation tests were also conducted. The selected Candida colony was inoculated in YEPD medium for subculture and the cultured organism was harvested. The organisms were homogenized, centrifuged and the supernatant was filtered. The filtrate was extracted in chloroform. The extract was centrifuged and the aqueous phase was dialyzed. The dialyzed crude enolase was subjected to SDS-PAGE. The Sabouraud's dextrose broth inoculated with vaginal swab showed turbid growth. The scraping from vagina showed typical smooth creamy white colonies with a characteristic yeast odour on Sabouraud's dextrose agar plate. On Hichrome candida agar the Candida growth appeared as glistening green colored. Gram stained smears from vaginal scraps showed appearance of fungus as yeast
\end{abstract}


budding. On corn meal agar the suspected Candida growth showed the formation of large, highly refractive, thick walled terminal chlamydospores. Germ tubes were seen as long tube like projections extending from the yeast cells on human serum inoculated with suspected strain of Candida. The carbohydrate assimilation tests were positive for dextrose, maltose, sucrose, galactose, xylose and trehalose, and negative for lactose, melibiose, ellobiose, inositol, reffinose and dulcitol. The carbohydrate fermentation tests showed positive for dextrose, maltose, galactose and trehalose, and negative for sucrose and lactose. SDS-PAGE for enolase from C. albicans showed a single polypeptide band of around $46-48 \mathrm{kDa}$.

Keywords: Candida albicans, Enolase, Vaginal-ulcer

\section{Introduction}

The yeast Candida albicans is commonly inhabits in oral and vaginal mucosa and gastrointestinal tract of human beings as one of the commensal organisms. It causes opportunistic infections in immuno-compromised patients, produces allergic reactions and rarely causes morbidity and mortality (Douglas, 1988). It also causes a variety of infections that range from mucosal candidiasis to life-threatening disseminated candidiasis (Dixon et al., 1996; O'Dwyer et al., 2007; Terrier et al., 2007).

The diagnosis of its deep seated infections remains a great challenge. One of the major reasons for the increase in Candida infections is the development of its resistant strains to azole drugs, such as fluconazole used in the prophylaxis and treatment of candidiasis (Diaz-Guerra et al., 1998; Shahid et al., 2006). The identification of invasive or disseminated candidiasis is based on clinical symptoms that are diffuse and not easily differentiated from those manifested by other infectious agents. Therefore considerable interest in the identification and characterization of antigens would be useful in the diagnosis and treatment of Candida infections.

It has been reported that in C. albicans and Candida tropicalis the cytosolic enzyme, enolase, was identified as an immuno-dominant antigen (Walsh et al., 199; Mitsutake et al., 1994; Angiolella, 1996). Candida enolase is a plasminogen- and plasmin-binding protein and the interaction of $C$. albicans enolase with the plasminogen system may contribute to invasion of the tissue barrier (Jong, 2003). Antibody to this bona fide cell wall protein is considered to be more predictive and specific as the cytoplasmic antigen is exposed only during invasive infection. Patients with localized candidiasis express only weak positive antibody titre (Van Deventer et al., 1993). In recent years Candida infection increases clinical awareness. Therefore, the present work was aimed to culture and identify C. albicans from patients with suspected invasive vaginal candidiasis, and separate enolase on SDS-PAGE to identify its molecular weight.

\section{Materials and Methods}

C. albicans strains were isolated from patients with clinical symptoms of vaginal ulcer and similar infections.

\subsection{Collection and processing of vaginal samples}

The suspected patients were used as subjects and the samples were collected and analyzed for C. albicans. The specimens were collected with meticulous care aseptically at the slit lamp.

\subsection{Culture test from vaginal swabs}

Sterile cotton swabs were prepared, gently smeared over the ulcers in the vaginal region and the swabs were immediately transferred to Sabouraud's Dextrose broth $(\mathrm{pH}, 5.6)$ containing dextrose $(4 \%)$, peptone $(1 \%)$ in double distilled water and incorporated with Chloramphenicol $(5.0 \mathrm{mg})$. The culture tubes were incubated at $37^{\circ} \mathrm{C}$ for $24-48$ hr.

\subsection{Culture test from vaginal scrapings}

Using a heat sterilized Kimura's platinum spatula of Bard Parker blade, vaginal scrapings were collected and the scrap material was streaked onto Sabouraud's dextrose agar plates as a fine C-streak.

\subsection{Preparation of Sabouraud's dextrose agar plates}

The Sabouraud's Dextrose agar consists of Sabouraud's dextrose broth $(\mathrm{pH}, 5.6)$ and $1.5 \%$ agar. This was autoclaved and cooled to $45^{\circ} \mathrm{C}$, and $5 \mathrm{ml}$ of sterile defibrinated sheep blood was added to it aseptically. It was mixed thoroughly and dispensed into plates without air bubbles. The plates were incubated at $37^{\circ} \mathrm{C}$ for $24-48 \mathrm{hr}$. The suspected isolates of Candida were sub cultured onto Sabouraud's agar plates.

\subsection{Differential identification of candida}

Hichrome Candida agar $(\mathrm{pH}, 6.5)$ containing $1.5 \%$ peptic digest of animal tissues, $0.1 \%$ dipotassium hydrogen phosphates, $1.2 \%$ chromogenic mixture, $0.05 \%$ Chloramphenicol and $1.5 \%$ agar in double distilled water was used for the presumptive identification of clinically important Candida species. The scraps were directly streaked on Hichrome Candida agar and incubated at $37^{\circ} \mathrm{C}$ for $48 \mathrm{hr}$. 


\subsection{Gram staining}

Smears from the vaginal scrapings were prepared on slides cleaned with alcohol. They then heat-fixed;-staining was done by flooding the smears with crystal violet solution for $1 \mathrm{~min}$ and then with Gram's iodine for 1 min. After washing, the smears were decolorized with $95 \%$ ethanol and counter strained with aqueous basic fuchsin. The slide was subjected to observation of Candida morphology under oil immersion objective lens (100 x) of a Bright Field microscope.

\subsection{Test for chlamydospore formation}

The suspected Candida cultures were inoculated on corn meal agar medium $(\mathrm{pH}, 7)$ containing $4 \%$ corn meal powder, $1 \%$ Tween 80 and $1.5 \%$ agar in double distilled water. The plates were incubated at $37^{0} \mathrm{C}$ for $48-72 \mathrm{hr}$.

\subsection{Test for germ tube formation}

The suspected Candida cultures were inoculated into $0.5 \mathrm{ml}$ of human serum in a small tube and incubated at $37^{\circ} \mathrm{C}$ for $2 \mathrm{hr}$. After desired period of incubation, a loop-full of culture was placed on a glass slide and overlaid with a cover-slip. The preparation was examined for germinating blastospores.

\subsection{Carbohydrate assimilation tests}

The mainstay of yeast identification to the species level is the carbohydrate assimilation test, which measures the ability of yeast to utilize a specific carbohydrate as the sole source of carbon in the presence of oxygen. Sugars used for assimilation tests include dextrose, maltose, sucrose, lactose, galactose, melibiose, cellobiose, inositol (a form of sugar, carbocyclic polyol, cyclohexanehexol), xylose, raffinose, trehalose and dulcitol (or galactitol, a sugar alcohol, the reduction product of galactose).

Candida cultures were suspended in saline $(\mathrm{NaCl})$ and to which $1.5 \mathrm{ml}$ of basal medium containing $67.8 \%$ yeast nitrogen base was added. This was then added to $13.5 \mathrm{ml}$ of molten, cooled agar containing $2 \%$ agar powder, mixed well, poured into Petri dish and allowed to solidify. After the medium was set, $20 \%$ sugar-soaked filter paper discs were placed on the medium. The plates were incubated at $25^{\circ} \mathrm{C}$ for $10-24 \mathrm{hr}$ and observed for the growth of Candida.

\subsection{Carbohydrate fermentation tests}

Fermentative yeasts recovered from clinical specimens produce carbon dioxide and alcohol. Production of gas rather than a $\mathrm{pH}$ shift is indicative of fermentation. Dextrose, maltose, sucrose, lactose, galactose and trehalose were used in the test.

The $5 \mathrm{ml}$ of carbohydrate $(\mathrm{pH}, 7.4)$ containing $1 \%$ peptone, $1 \%$ sugar, $0.3 \%$ beef extract and $0.5 \% \mathrm{NaCl}, 0.2 \%$ Bromothymol blue in distilled water medium was dispensed in sterilized Durham tube and $0.2 \mathrm{ml}$ of saline suspension of the test organism was added and incubated at $37^{0} \mathrm{C}$ for 10 days.

\subsection{Subculture and harvesting of yeast cells}

The selected organism was inoculated in yeast-extract-peptone-dextrose (YEPD) culture medium (pH, 7) containing $1 \%$ yeast extract, $2 \%$ peptone and $2 \%$ dextrose, and incubated at $30^{\circ} \mathrm{C}$ for $24 \mathrm{hr}$ in a mechanical shaker at $150 \mathrm{rpm}$. A $10 \mathrm{ml}$ starter culture provided the basis for $500 \mathrm{ml}$ Candida culture to be grown under similar conditions in a 21 Erlenmeyer flask.

The C. albicans culture was harvested from the 21 Erlenmeyer flask by centrifugation at $10,000 \mathrm{rpm}$ for $15 \mathrm{~min}$ at $4^{0} \mathrm{C}$. The cells were washed with distilled water and again collected by centrifugation. The supernatant was discarded and the cell pellets were re-suspended in protein-extraction buffer $(\mathrm{pH}, 6.5)$ containing $0.2 \%$ Bis-Tris. The yeast cells were centrifuged as described above then re-suspended and pooled for further processing.

\subsection{Cell fractionation}

The organisms were suspended in a breaking buffer $(\mathrm{pH}, 6.8)$ containing $62.5 \mathrm{mM}$ Tris-HCl buffer, $15 \%$ glycerol, $1 \mathrm{mM}$ dithiotheritol and $20 \mathrm{mg}$ of phenyl methyl sulfonyl flouride and broken by mechanical disruption in a Braun's homogenizer for $2 \mathrm{~min}$ with intermittent cooling in the presence of glass beads $0.45 \mathrm{~mm}$ in dia. After disruption of the cells, the glass beads and unbroken cells were removed by centrifugation at $500 \mathrm{x} \mathrm{g}$. The homogenate was then centrifuged at $6000 \mathrm{x}$ g for $20 \mathrm{~min}$ and the pellet was collected. The supernatant containing the soluble protein fraction was recovered and passed through a $0.45 \mu \mathrm{m}$ filter membrane. The filtrates were then extracted with an equal volume of chilled chloroform. Following centrifugation at $4^{0} \mathrm{C}$ for $15 \mathrm{~min}$ at $2000 \mathrm{xg}$, the upper aqueous phase was aspirated and transferred to a dialysis tube. The crude protein fraction was dialyzed in column binding buffer (20 mM Bis-Tris, $\mathrm{pH}$ 6.5) for $24 \mathrm{hr}$. The dialysed crude enolase was subjected to Sodium Dodecyl Sulphate - Poly Acrylamide Gel Electrophoresis (SDS - PAGE). 


\subsection{SDS - PAGE}

SDS - PAGE was performed following the method of Laemmli (1970). Equal amount of sample loading buffer was added to the enolase samples ( $20 \mu \mathrm{g}$ protein). The samples were boiled for $1 \mathrm{~min}$ and loaded on $12 \%$ SDS - PAGE. Protein standard of known molecular weight was also run parallel. The wells and tanks were filled with electrophoresis running buffer. The protein was allowed to isolate at $50 \mathrm{~V} \mathrm{DC}$ in the stacking region and $100 \mathrm{~V} \mathrm{DC}$ in the separating gel for about 3 hrs. The gel was stained overnight in Coomassie Brilliant Blue solution. The stained gel was de-stained in methanol - acetic acid solution until the gel background turns clear for visualizing the polypeptide band.

\section{Results and Discussion}

Candida is a dimorphic organism, meaning it can exist in two shapes and forms simultaneously. One form is a yeast-like state that is a non-invasive, sugar fermenting organism. The other is a fungal form that produces very long root-like structures, called rhizoids that can penetrate the mucosa and is invasive.

Healthy immune system prevents this yeast from becoming an infectious fungus. It is when our bodies lose their proper immune protection or the intestinal $\mathrm{pH}$ is altered unfavourably, that the organism can change from the yeast form to the fungal form. When this happens, the now-parasitic fungal form penetrates the gastrointestinal mucosa and breaks down the boundary between the intestinal tract and the rest of the circulation in our bodies. This allows partially digested dietary proteins to travel into the blood stream, where they exert a powerful antigenic (antibody-stimulating) assault on the immune system. It has been officially estimated that about $80 \%$ of the population may have candidiasis that is out of control.

The immune system is attacked by Candida as a result of the prolonged use of antibiotics, taking steroids or oral contraceptives on a regular basis, or due to high sugar diet. It is also known that Candida increases its numbers during periods of stress and lowered immune states.

Fungal infection of vagina is sometimes called a thrush. Candidiasis is also known as yeast infection is a common fungal infection that occurs when there is overgrowth of the fungus called Candida which is always present in the body in small amounts. However, when an imbalance occurs, such as when the normal acidity of the vagina changes or when hormonal balance changes, Candida can multiply. When this happens, symptoms of candidiasis appear. This may include depression, dry, itchy, flaky skin, anxiety, recurring irritability or mood swings, heartburn, indigestion, lethargy, food and environmental allergies, joint soreness, chest pain or other skin problems, recurring cystitis/vaginal infections, premenstrual tension and menstrual problems. Immune suppression, AIDS, diabetes and thyroid disorder may also cause candidiasis.

Vaginal thrush was characterized by typical white lesions developed on the epithelial surfaces of vulva, vagina and cervix. In the present study, the Sabouraud's dextrose broth inoculated with swab from the lesions of vagina showed turbid growth after incubation. On Sabouraud's dextrose agar, the scrapings from lesions of vagina showed typical smooth creamy white colonies with a characteristic yeast odour. Scrapings from the lesions of vagina were examined in the Gram stained smear. The fungus appeared as budding yeast cells and pseudomycelium was present in most cases (Fig. 1). On Hichrome candida agar, the scrapings from vagina produced glistening green color colonies (Fig.2). The suspected stains of $C$. albicans isolates were grown on the corn meal agar. It showed the formation of large, highly refractive and thick walled terminal chlamydospores (Fig. 3). When the suspected C. albicans was inoculated with human serum the formation of germ tubes was seen as long tube like projections extending from the yeast cells. There was no constriction at the point of attachment to the yeast cells. The germ tubes were formed within two hours of incubation in C. albicans (Fig. 4).

The carbohydrate assimilation tests for C. albicans are presented in table 1. It shows that the test was positive for dextrose, maltose, sucrose, galactose, xylose and trehalose. At the same time, the tests were negative for lactose, melibiose, cellobiose, inositol, reffinose and dulcitol. Similarly, the carbohydrate fermentation tests for C. albicans are presented in table 2. The tests for fermentation of dextrose, maltose, galactose and trehalose were positive but negative for fermentation of sucrose and lactose.

The SDS-PAGE profile of the crude sample prepared from C. albicans for enolase showed several polypeptide bands from $205 \mathrm{kDa}$ to $29 \mathrm{kDa}$. Among these, the prominently resolved single polypeptide band of around $48 \mathrm{KDa}$ was considered as enolase (EC: 4.2.1.11) (Fig. 5). This confirmation was based on the reports in the literature (Strockbine $e t$ al., 1984; Walsh et al., 1988, 1991; Savolainen et al., 1990; Sundstrom and Aliaga, 1992; Mason et al., 1993; Ito et al., 1995; Chang et al., 2002). The enolase from the pathogenic yeast C. albicans has been identified as an immunodominant antigen in disseminated infection and in allergic disease (Mitsutake et al., 1994). The Candida species such as C. glabrata, C. tropicalis, C. krusei, C. parapsilosis and C. lusitaniae are increasingly being identified as significantly causing infections in humans (Hazen and Hazen, 1992).

The cell wall of Candida is a dynamic and multilayered structure located external to the plasma membrane. The cell wall of C. albicans is composed of different types of carbohydrates ( $80-90 \%$ ): (i) Mannan or polymers of mannose 
covalently associated with proteins to form glycoproteins, also referred to as mannoproteins, (ii) $\alpha$-glucans that are branched polymers of glucose containing $\alpha-1,3$ and $\alpha-1,6$ linkages, and (iii) chitin, which is an un-branched homopolymer of N-acetyl-D-glucosamine (Glc-NAc) containing $\alpha-1,4$ bonds (Gomez et al., 1996). The other constituents are proteins $(6-25 \%)$ and lipids $(1-7 \%)$ which are present as minor wall constituents (Shepherd, 1987). Yeast cells and germ tubes are similar in their cell wall composition, although the relative amounts of $\alpha$-glucans, chitin and mannan may vary with morphology. Although glucans are present in greater abundance than mannan in C. albicans, they are immunologically less active (Poulain et al., 1985).

The enzyme enolase was reported to be associated with glucan in the inner layers of the cell wall as well as in culture supernatants. Enolase seems to be the most immunodominant antigen in humans. In mice, enolase stimulates both humoral and cellular immune responses. The glycolytic enzyme, enolase catalyzes the reversible dehydration of 2-phospho-D-glycerate to high-energy phosphoenolpyruvate (Matthews et al., 1984). Characterization of antigenic components in cytoplasmic extracts of $C$. albicans that were recognized in sera from patients with disseminated candidiasis has been reported (Strockbine et al., 1984). Further, they reported that these patients had circulating antibodies directed against a $48 \mathrm{KDa}$ protein antigen purified by anion-exchange chromatography from the Candida extract. Individuals colonized with $C$. albicans without evidence of candidiasis did not have detectable levels of antibodies to this antigen, which was subsequently identified as enolase (Franklyn et al., 1990). Circulating anti enolase antibodies may have potential value for the diagnosis of candidiasis (Mitsutake et al., 1994).

Antigenemia with the 48-KDa antigen has been reported in disseminated candidiasis in the absence of fungemia and correlated with deep tissue infection (Walsh et al., 1988). C. albicans enolase antigenemia is a marker for deep tissue invasion even in the absence of fungemia (Walsh et al., 1991). Some major protein allergens of C. albicans have been identified by immunoblotting with anti-human IgE antibodies. For instance, in a study, serum samples from asthmatic patients reacted with fractions containing a $46 \mathrm{KDa}$ protein (Walsh et al., 1991). The enzyme enolase from Saccharomyces cerevisiae and C. albicans acts as a major allergen and such allergen detected was believed to be enolase, a $46 \mathrm{KDa}$ protein (Savolainen et al., 1990; Ito et al., 1995; Nittner-Marszalska et al., 2001; Kustrzeba-Wojcicka and Golczak, 2000; Chang et al., 2002). In S. cerevisiae the glycolytic enzyme, enolase has been localized as a $47 \mathrm{kDa}$ protein (Pardo et al., 2000; Kim and Park, 2004).

The humoral and cellular immune responses to enolase were evident in germ-free mice colonized with C. albicans. The lymphocytes from intravenously challenged mice responded to enolase as an immunodominant humoral antigen (Del Prete, 1992). Although the cytoplasmic location of enolase appeared to be established, enolase was detected by radioimmuno precipitation in cell wall extracts obtained after digestion of the wall $\alpha$ - glucan network with $\alpha$ glucanase, zymolyase (Stec and Lebioda, 1990; Sundstrom and Aliaga, 1992; Angiolella et al., 1996). The release of enolase may be important in defining the selective stimulation of the host antifungal response during infection. It has recently been reported that anti-enolase antibodies may have an immunoprotective effect in mice. Cilofungin, a lipopeptide antibiotic affecting $\alpha-1$, 3-D-glucan synthesis inhibited the incorporation of a 46 to $48 \mathrm{KDa}$ glucan-associated protein, a cell wall associated form of enolase (Mason et al., 1993).

To summarize, $C$. albicans were isolated from patients with invasive candidiasis and characterized. Suspected $C$. albicans strains were selectively isolated on Hichrome Candida Agar and identified. The organism was grown on YEPD medium and harvested. The cell pellets were suspended in protein-extraction buffer. The cells were again suspended in the breaking buffer and broken by mechanical disruption with glass beads. The homogenate was centrifuged and the supernatant containing the soluble protein fraction was passed through the membrane filter. The filtrate was subjected to extraction with chloroform. The dialysed crude enolase cytoplasmic extract was subjected to SDS - PAGE along with standard markers and the $C$. albicans enolase was confirmed as a single polypeptide band of around $48 \mathrm{KDa}$.

Further, to investigate the immunological cross reactivity of enolase with appropriate antibodies and other biochemical studies, purification of enolase is required. Such type of investigation is very much needed to study the pathology of $C$. albicans. Immunological relevance and interspecies relationship of the Candida enolase antigens can also be investigated.

\section{Acknowledgement}

Mr. C. Sureshkumar, M.Sc., M.Phil., Microbiologist, AR Labs and Research Foundation, Salem, Tamilnadu, India is gratefully acknowledged for providing technical support.

\section{References}

Angiolella, L., Facchin, M., Stringaro, A., Maras, B., Simonetti, N., \& Cassone, A. (1996). Identification of a glucanassociated enolase as a main cell wall protein of Candida albicans and an indirect target of lipopeptide antimycotics. $J$. Infect. Dis., 173, 684-690.

Chang, C.Y., Chou, H., Tam, M.F., Tang, R.B., Lai, H.Y., \& Shen, H.D. (2002). Characterization of Enolase Allergen from Rhodotorula mucilaginosa. J. Biomedical Sci., 9, 645-655. 
Del Prete, G. (1992). Human TH1 and TH2 lymphocytes: their role in the pathophysiology of atopy. Allergy, 47, $450-455$.

Diaz-Guera, T.M., Martinez-Suarez, J.V., Laguna, F., Valencia, E., \& Rodriguez-Tudela, J.L. (1998). Change in fluconazole susceptibility patterns and genetic relationship among oral Candida albicans isolates. AIDS, 12, 1601-1610.

Dixon, D.M., McNeil, M. M. M., Cohen, M.L., Gellin, B.G., \& LaMontagne, J.R. (1996). Fungal infections: a growing threat. Public Health Rep., 111, 226-235.

Douglas, L.J. (1988). Candida proteinases and candidiasis. Crit. Rev. Biotechnol., 8, 121-129.

Franklyn, K.M., Warmington, J.R., Ott, A.K., \& Ashman, R.B. (1990). An immunodominant antigen of Candida albicans shows homology to the enzyme enolase. Immunol. Cell Biol., 68, 173-178.

Gomez, M.J., Torosantucci, A., Arancia, S., Maras, B., Parisi B., \& Cassone, A. (1996). Purification and biochemical characterization of a 65- kilodalton mannoprotein (MP65), a main target of anti-candida cell mediated immune response in humans. Infect. Immun., 64, 2577-2584.

Hazen, K.C., \& Hazen, B.W. (1992). Hydrophobic surface protein masking by the opportunistic fungal pathogen, Candida albicans. Infect. Immun., 60, 1499-1508.

Ito, K., Ishiguro, A., Kanbe, T., Tanaka, K., \& Torii. S. (1995). Detection of IgE antibody against Candida albicans enolase and its cross reactivity to Saccharomyces cerevisiae enolase. Clin. Exp. Allergy, 25, 522-528.

Jong, A.Y., Chen, S.H.M., Stins, M.F., Kim, K.S., Tuan, T.L., Huang, S.H. (2003). Binding of Candida albicans enolase to plasmin (ogen) results in enhanced invasion of human brain microvascular endothelial cells. J. Med. Microbiol, 52, 615-622.

Kim, K-H., \& Park. H-M. (2004). Enhanced secretion of cell wall bound enolase into culture medium by the sool-1 mutation of Saccharomyces cerevisiae. J. Microbiol., 42, 248-252.

Kuztrzeba-Wojcicka, I., \& Golczak, M. (2000). Enolase from Candida albicans - purification and characterization. Comparative Biochem. Physiol, 126, 109-120.

Laemmli, U.K. (1970). Changes of structural Proteins during the assembly of the head of bacteriophage $\mathrm{T}_{4}$ Natur, 227 , $680-685$.

Mason, A.B., Buckley, H.R., \& Gorman, J.A. (1993). Molecular cloning and characterization of the Candida albicans enolase gene. J. Bacteriol, 175, $2632-2639$.

Matthews, R.C., Burnie, J.P., \& Tabaqchali, S. (1984). Immunoblot analysis the serological response in systemic candidiasis. Lancet, 2, $1415-1418$.

Mitsutake, K., Kohno, S., Miyazaki, T., Miyazaki, H., Maesaki, S., \& Koga, H. (1994). Detection of Candida enolase antibody in patients with candidiasis. J. Clin. Lab. Anal., 8, $207-210$.

Nittner-Marszalaska, M., Wojcicka-Kustrzeba, I., Bogacka, E., Patkowski, J., \& Dobek, R. (2001). Skin prick test response to enzyme enolase of the baker's yeast (Saccharomyces cerevisiae) in diagnosis of respiratory allergy. Med. Sci. Monit., 7, 121-124.

O’Dwyer, D.T., McElduff, P., Peterson, P., Perbeentupa, J., \& Crack, P.A. (2007). Pituitary autoantibodies in autoimmune polyendocrinopathy - candidiasis - ectodermal dystrophy (APECED). ACTA BIOMED, 78, 248-254.

Pardo, M., Ward, M., Bains, S., Molina, M., Blackstock, W., Gil, C., \& Nombela, C. (2000). A proteomic approach for the study of Saccharomyces cerevisiae in the cell wall biogenesis. Electrophoresis, 21, 3396-3410.

Poulain, D., Hopwood, \& Vernes, A. (1985). Antigenic variability of Candida albicans. Crit. Rev. Microbiol., 12, 223-270.

Savolainen J.J., Viander, M., \& Koivikko, A. (1990). IgE, IgA, and IgG antibody responses to carbohydrate and protein antigens of Candida albicans in asthmatic children. Allergy, 45, 54-63.

Shahid, M., Malik, A., Rizvi, M.W., \& Singhai, M. (2006). Protein profile of a Fluconazole-resistant Candida albicans isolated from HIV-1 infected patient: Evaluation of protein extraction methods and development of a simple procedure. Global J. Biotech. Biochem., 1, 01-06.

Shepherd, M.G. (1987). Cell envelope of Candida albicans. Crit. Rev. Microbiol., 15, 7-25.

Stec, B., \& Lebioda, L. (1990). Refind structure of yeast apo - enolase at $2.25 \mathrm{~A}^{\mathrm{o}}$ resolution. J. Mol. Biol., 211, 235-248.

Strockbine, N.A., Largen, M.T., Zweibel, S.M, \& Buckley, H.R. (1984). Identification and molecular weight characterization of antigens from Candida albicans that are recognized by human sera. Infect. Immun., 43, 715-721. 
Sundstrom, P.M., \& Aliaga, G.R. (1992). Molecular cloning of cDNA and analysis of protein secondary structure of Candida albicans enolase, an abundant immunodominant glycolytic enzyme. J. Bacteriol., 174, 6789-6799.

Sundstrom, P.M., \& Aliaga, G.R. (1994). A subset of proteins found in culture supernatants of Candida albicans includes the abundant, immunodominant glycolytic enzyme enolase. J. Infect. Dis., 169, 452-456.

Terrier, B., Degand, N., Guilpain, P., Servettaz, A., Guillevin, L., \& Mouthon, L. (2007). Alpha-enolase: A target of antibodies in infectious and autoimmune diseases. Autoimmunity Reviews, 6, 176-182.

Van Deventer, A.J.M., Van Vliet, H.J.A, Voogd, L., Hop, W.C.J., \& Gossens, W.H.F. (1993). Increased specificity of antibody detection in surgical patients with invasive candidiasis with cytoplasmic antigens depleted of mannan residues. J. Clin. Microbiol., 31, 994-997.

Walsh, T.F., Buckley, H.R., Wom-Eng, M., Johnson, D.E., Maret, M., \& Gary, P. (1988). Analysis of a 48 KDa cytoplasmic antigens of Candida albicans in experimental candidiasis. J. Gen. Microbiol., 135, 2509 - 2518.

Walsh. T.J., Hathorn, J.W., Sobel, J.D., Merz, W.G., Sanchez, V., Maret, S.M., Buckley, H.R., Pfaller, M.A., Schaufele, R., Silva, C., Navarro, E., Leccoiones, L., Chandrasekar, P., Lee, J., \& Pizzo, P.A. (1991). Detection of circulating Candida enolase by immunoassay in patients with cancer and invasive candidiasis. New England J. Med., 324, 1026 1031.

Table 1. Carbohydrate assimilation tests for C. albicans

\begin{tabular}{|l|l|c|}
\hline \multicolumn{1}{|c|}{ Species } & \multicolumn{1}{|c|}{ Substance } & Detection \\
\hline \multirow{5}{*}{ C. albicans } & Dextrose & $+\mathrm{ve}$ \\
\cline { 2 - 3 } & Maltose & $+\mathrm{ve}$ \\
\cline { 2 - 3 } & Sucrose & $+\mathrm{ve}$ \\
\cline { 2 - 3 } & Lactose & $-\mathrm{ve}$ \\
\cline { 2 - 3 } & Galactose & $+\mathrm{ve}$ \\
\cline { 2 - 3 } & Melibiose & $-\mathrm{ve}$ \\
\cline { 2 - 3 } & Cellobiose & $-\mathrm{ve}$ \\
\cline { 2 - 3 } & Inositol & $-\mathrm{ve}$ \\
\cline { 2 - 3 } & Xylose & $+\mathrm{ve}$ \\
\cline { 2 - 3 } & Reffinose & $-\mathrm{ve}$ \\
\cline { 2 - 3 } & Trehalose & $+\mathrm{ve}$ \\
\cline { 2 - 3 } & Dulcitol & $-\mathrm{ve}$ \\
\hline
\end{tabular}

Table 2. Carbohydrate fermentation tests for C. albicans

\begin{tabular}{|c|l|c|}
\hline \multicolumn{1}{|c|}{ Species } & \multicolumn{1}{|c|}{ Substance } & Detection \\
\hline \multirow{4}{*}{ C. albicans } & Dextrose & $+\mathrm{ve}$ \\
\cline { 2 - 3 } & Maltose & $+\mathrm{ve}$ \\
\cline { 2 - 3 } & Sucrose & $-\mathrm{ve}$ \\
\cline { 2 - 3 } & Lactose & $-\mathrm{ve}$ \\
\cline { 2 - 3 } & Galactose & $+\mathrm{ve}$ \\
\cline { 2 - 3 } & Trehalose & $+\mathrm{ve}$ \\
\hline
\end{tabular}




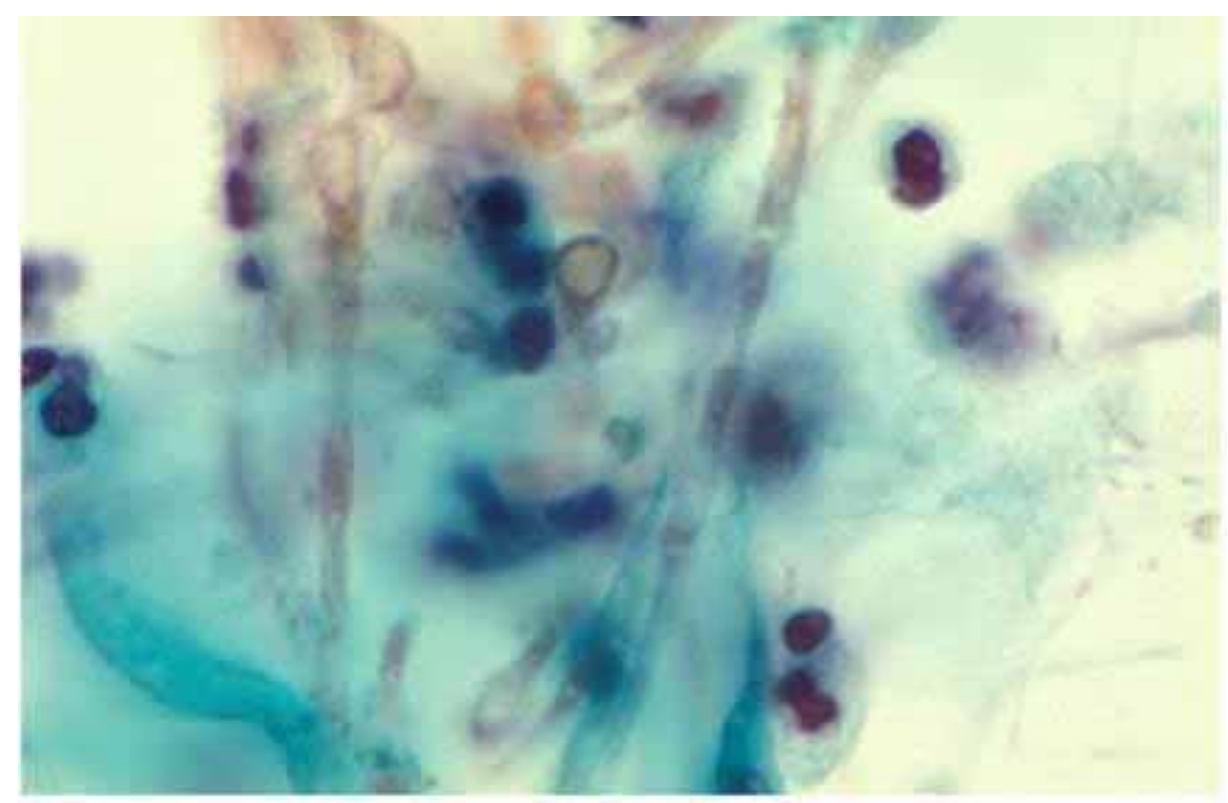

Figure 1. Budding yeast cells with pseudohyphae of $C$. albicans

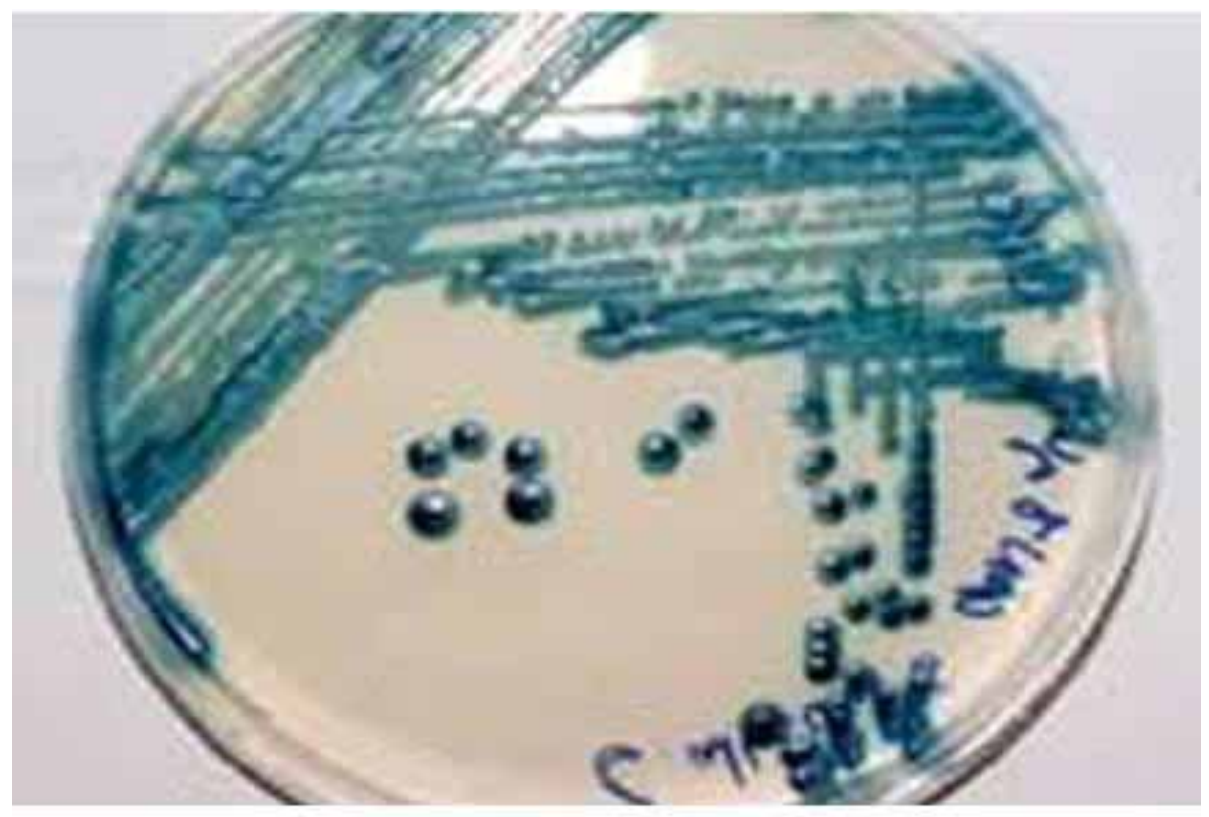

Figure 2. Glistening green colour colonies produced by C. albicans on Hithrome canaida agar 


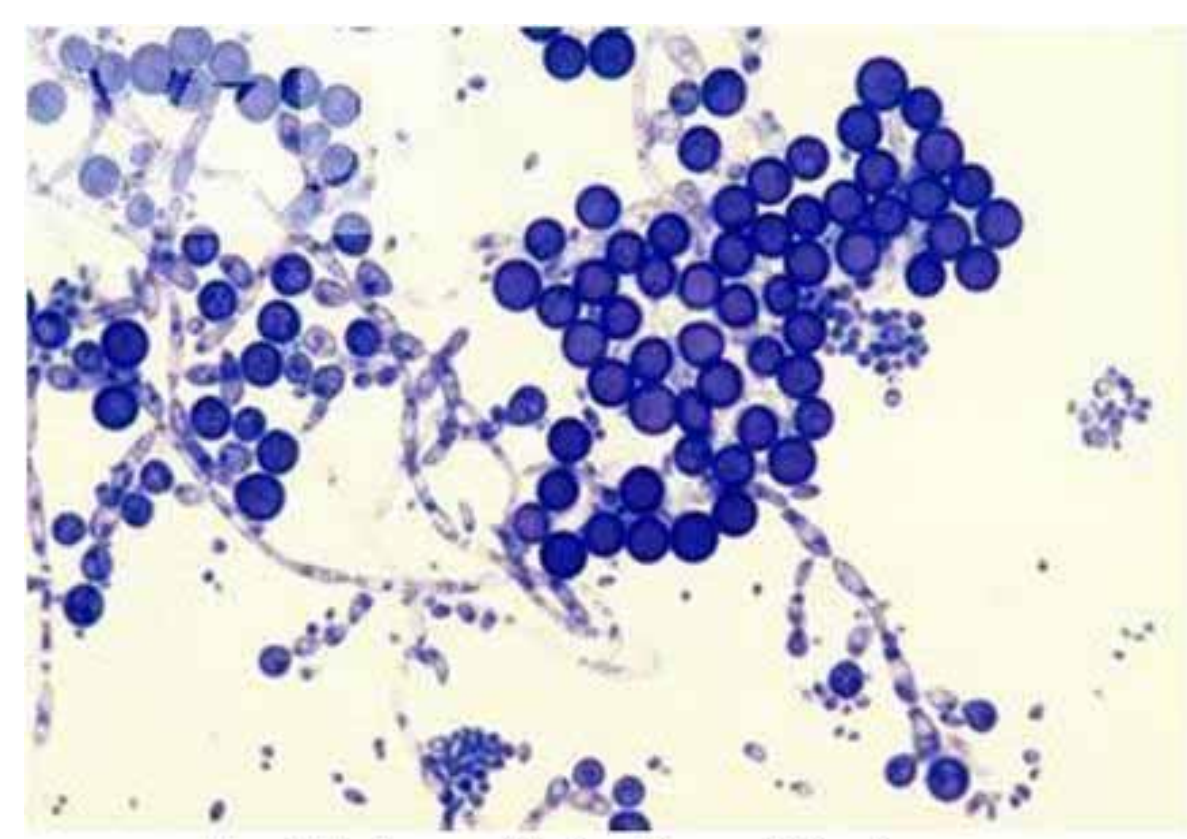

Figure 3. C. albicans with thick walled terminal chlamydospores

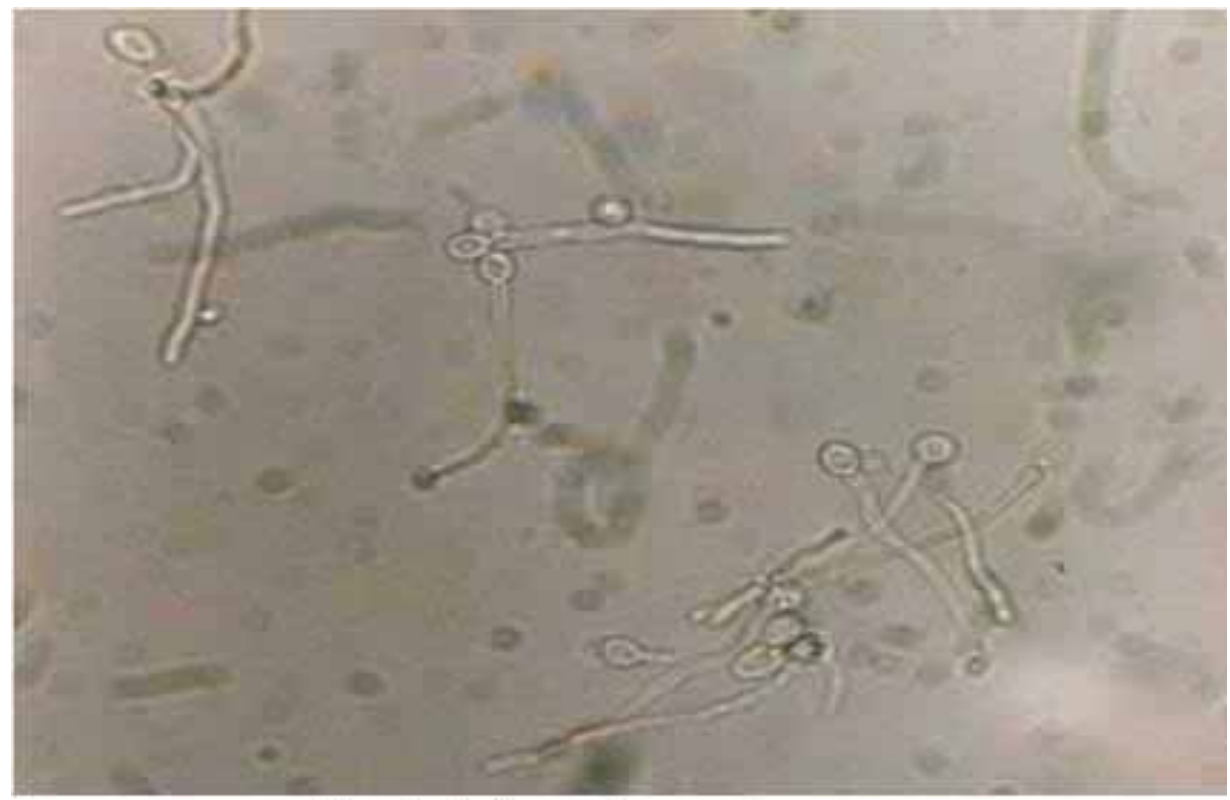

Figure 4. C. albicans with germ tubes 


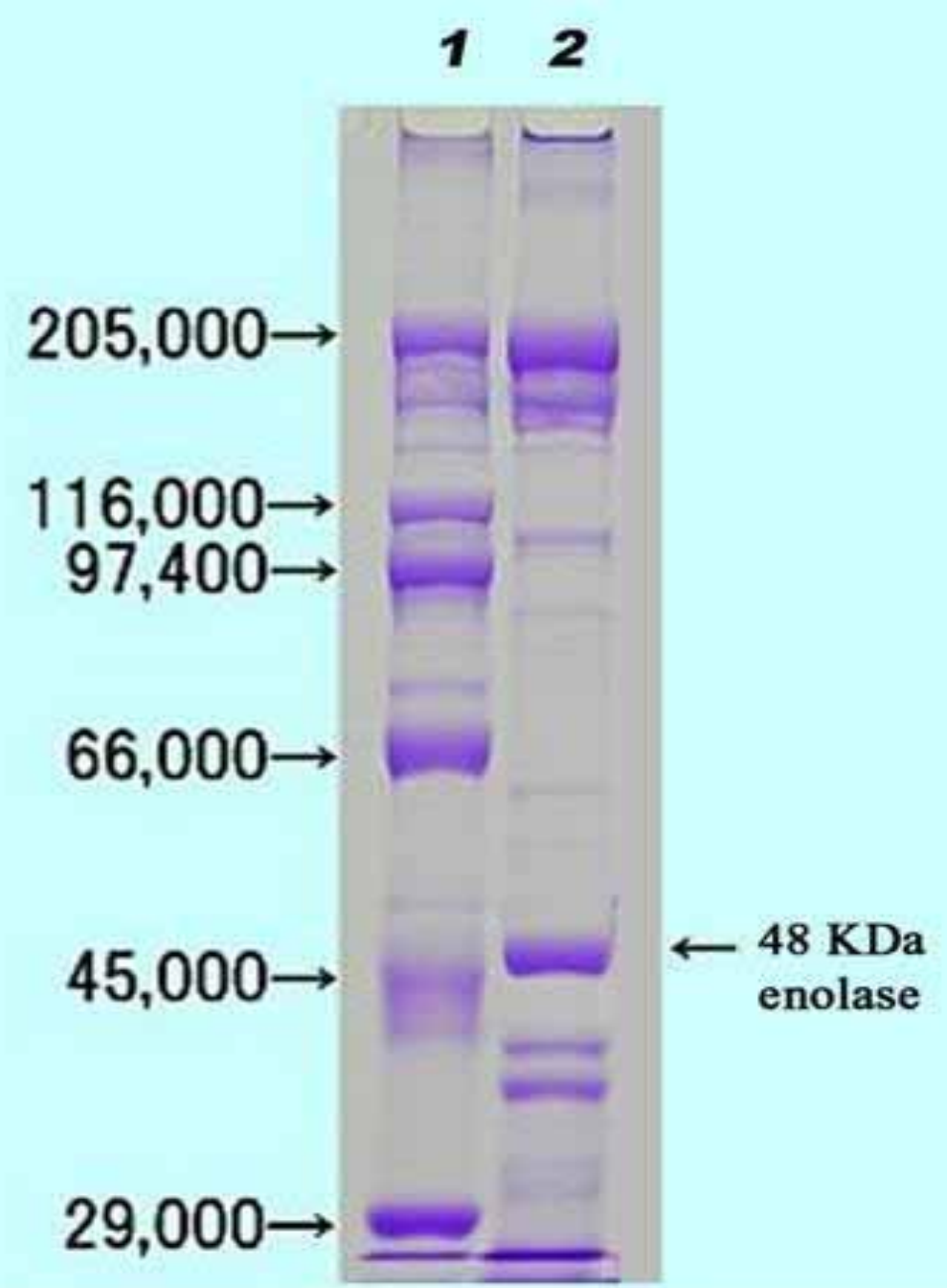

Figure 5. SDS-PMGE profile of crude enolase from C. albicans

(1. standard protein markers: 2 . crude enolase sample) 